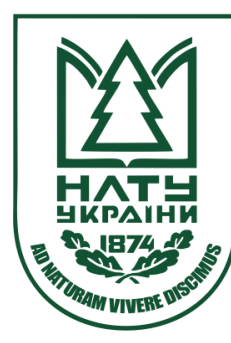

Науковий вісник НлтУ України Scientific Bulletin of UNFU

ISSN 1994-7836 (print)

https://nv.nltu.edu.ua

https://doi.org/10.36930/40300515

Article received 03.11.2020 p.

Article accepted 05.10.2020 p.

UDC 004.[021+942]

@ Correspondence author

A. G. Kazarian

artem.kazarian@gmail.com

В. М. Теслюк, А. Г. Казарян

Національний університет "Львівська політехніка", м. Львів, Україна

\title{
ВИБІР ОПТИМАЛЬНОГО ТИПУ ШТУЧНОЇ НЕЙРОННОЇ МЕРЕЖІ ДЛЯ АВТОМАТИЗОВАНИХ СИСТЕМ "РОЗУМНОГО" БУДИНКУ
}

Розроблено метод вибору оптимального типу ШНМ, ідеєю якого є практичне використання декількох типів ШНМ, подальшого обчислення похибок роботи кожного типу з використанням ідентичних наборів даних для навчання ШНМ, що унеможливлює вплив на результати роботи алгоритму і специфіки даних у навчальній вибірці. Запропонований метод дає змогу визначити оптимальний тип ШНМ для керування побутовими приладами у будинку. Розглянуто особливості процесу розроблення програмного забезпечення, що дає змогу провести процеси навчання, випробування та отримати вихідні результати роботи алгоритму штучної нейронної мережі. Вибір штучної нейронної мережі використовують для автоматизації обчислення значень оптимальних температурних режимів у кімнатах будинку, налаштувань параметрів освітлювальних приладів та режимів роботи системи безпеки "розумного" будинку. Наведено результати дослідження взаємозв'язку між різними типами нейронних мереж, кількістю внутрішніх шарів штучної нейронної мережі і кількістю нейронів на кожному внутрішньому шарі та зміни похибки обчислень параметрів налаштувань відносно очікуваних результатів роботи. Вирішення кожної окремої поставленої задачі за допомогою систем "розумного" будинку потребує використання різних алгоритмів машинного навчання. Великі обсяги даних, що генеруються у системах "розумного" будинку, та різноманітність типів $\mathrm{i}$ форматів цих даних не дає змоги створити універсальний автоматизований механізм з використанням алгоритмів штучного інтелекту, який вирішував би проблеми безпеки, енергоефективності та підтримки комфортних умов проживання користувачів. Тому використання запропонованого методу вибору оптимального типу нейронної мережі, що найкраще підходить для вирішення кожної окремої задачі, забезпечує високі показники ефективності роботи систем "розумного" будинку з мінімальними значеннями похибки отриманих автоматизованих рішень порівняно з рішеннями, що прийняла людина.

Ключові слова: системи інтелектуального будинку; машинне навчання; штучний інтелект; нейронна мережа прямого поширення; рекурентна нейронна мережа; довга короткочасна пам'ять; вентильний рекурентний вузол.

\section{Вступ}

На сьогодні системи "розумного" будинку зайняли одне 3 ключових ніш серед розробок у сфері інформаційних технологій $[4,14,20]$. Такі системи безперервно генерують потік даних, який може бути використано для забезпечення енергоефективності [15], оптимізації температурного режиму, освітлення, аудіо- та відео супроводу та визначення правил безпеки охоронної системи "розумного" будинку. Сфера застосування систем "розумного" будинку може бути розширена завдяки використанню у комерційних цілях через інтеграцію в інфраструктуру таких приміщень, як: офіси, магазини, склади, державні установи, торгово-розважальні комплекси тощо [5].

Об'єкт дослідження - штучні нейронні мережі, що використовують для автоматизації процесу прийняття рішень у системах "розумного" будинку.

Предмет дослідження - методи і засоби створення різних типів штучних нейронних мереж, результати роботи яких будуть використані під час вирішення окремих конкретних поставлених завдань сфери роботи сис- тем "розумного" будинку.

Мета роботи - розробити метод пошуку типу штучної нейронної мережі, використання якої буде забезпечувати отримання найефективніших результатів для виконання функцій систем "розумного" будинку.

Для досягнення зазначеної мети визначено такі основні завдання дослідження: здійснити огляд наявних типів штучних нейронних мереж; проаналізувати результати ефективності використання кожного типу штучної нейронної мережі для вирішення окремо поставлених задач сфери роботи систем "розумного" будинку; розробити метод вибору оптимального типу штучної нейронної мережі залежно від поставленої задачі, що потребує автоматизованого прийняття рішення системою "розумного" будинку.

Наукова новизна отриманих результатів дослідження - вперше розроблено метод пошуку оптимального типу штучної нейронної мережі для вирішення окремих завдань сфери роботи систем "розумного" будинку.

Практична значущість результатів дослідження розроблений метод $\epsilon$ універсальним для підтримки процесів прийняття рішень у автоматизованих системах

\section{Інформація про авторів:}

Теслюк Василь Миколайович, д-р техн. наук, професор, завідувач кафедри автоматизованих систем управління.

Email: vasyl.teslyuk@gmail.com; https://orcid.org/0000-0002-5974-9310

Казарян Артем Геннадійович, аспірант, кафедра автоматизованих систем управління. Email: artem.kazarian@gmail.com

Цитування за ДСту: Теслюк В. М., Казарян А. Г. Вибір оптимального типу штучної нейронної мережі для автоматизованих систем "розумного" будинку. Науковий вісник НЛтУ України. 2020, т. 30, № 5. С. 90-93.

Citation APA: Teslyuk, V. M., \& Kazarian, A. G. (2020). Development of optimal artificial neural network type selection method for usage in smart home systems. Scientific Bulletin of UNFU, 30(5), 90-93. https://doi.org/10.36930/40300515 
"розумного" будинку без обмежень у специфіці поставлених завдань, таких як безпека, енергоефективність тощо.

Аналіз останніх досліджень та публікацій. У наукових роботах $[2,7]$ описано процес синтезу систем "розумного будинку" з використанням технологій машинного навчання, а також деякі практичні реалізації цієї ідеї серед таких розробок, як Nest Thermostat [22]. Відповідна розробка використовує алгоритми машинного навчання для адаптації налаштувань, згідно із вподобаннями користувачів та поточної пори року. Наступна розробка Netatmo [23] дає змогу ідентифікувати присутність у приміщеннях визначених користувачів, за допомогою технологій розпізнавання обличчя та попереджати власника, коли у домі з'являється не ідентифікована особа; Amazon Echo [1] та Google Home [9] дають змогу керувати приладами сторонніх розробників за допомогою голосових команд; Klug Home використовує алгоритми машинного навчання для встановлення температурних режимів кондиціонера, яким надають перевагу користувачі, враховуючи час доби та активність людей у приміщенні, а також для виявлення аномальних збільшень споживання електроенергії [17]. Особливістю наявних продуктів $є$ те, що вони взаємодіють 3 обмеженою кількістю приладів будинку, тому розроблення комплексного рішення управління "розумним" будинком з використанням алгоритмів машинного навчання на сьогодні $є$ актуальним завданням. Під час розв'язання задач подібного типу часто використовують алгоритми штучної нейронної мережі, які, відповідно, поділяють на декілька типів. Ці алгоритми застосовують у різних сферах автоматизації процесів життєдіяльності людини. Під час синтезу комплексного рішення, яке орієнтоване на автоматизацію налаштування різних побутових приладів у будинку, існує проблема вибору оптимального типу штучної нейронної мережі, яка одночасно забезпечить найкращі результати роботи під час налаштування оптимального температурного режиму, режиму освітлення та режиму системи безпеки у будинку.

\section{Результати дослідження та їх обговорення}

математична формалізація задачі. Однією 3 найпоширеніших задач, яку розв'язують системи "розумного" будинку, є автоматизація змін налаштувань побутових приладів відповідно до внутрішньої логіки функціонування системи та забезпечення комфортних умов проживання мешканців будинку. Сформульовано задачу розроблення системи "розумного" будинку, з використанням алгоритмів на основі штучних нейронних мереж, для керування побутовими приладами та налаштування системи безпеки будинку. Тобто метою є отримати найменше значення похибки $\left(\Delta x_{\min }\right)$ між значеннями параметрів налаштувань приладів у будинку, розрахованими з використанням алгоритму машинного навчання $\left(x_{\text {авт }}\right)$ та очікуваних мешканцями будинку параметрів $\left(x_{\text {очік }}\right)$. Для розв'язання поставленої задачі використали кілька $(n)$ типів штучних нейронних мереж, 3 аналізом та порівнянням бажаних і реально отриманих результатів роботи кожного типу нейронної мережі, в процесі автоматизованого керування режимами термостату, освітлювальних приладів та сигналізації, окремо для кожної з поставлених задач:

$$
\Delta x_{\min }=\frac{1}{n} \sum_{i=0}^{n}\left|x_{a B m}^{(i)}-x_{o u i k}^{(i)}\right| .
$$

Під час виконання дослідження вибрали набір історичних даних з 7510 записів параметрів сенсорів та приладів будинку. Дані отримані з набору, що збирали впродовж року з 200 давачів у дослідницьких лаборатоpiяx Mitsubishi Electric Research Labs та які було викладено у відкритий доступ [19]. Для проведення процесу навчання різних типів нейронних мереж використовували ідентичну навчальну вибірку. Такий підхід унеможливлює вплив на результати роботи алгоритму ШНМ специфіки даних, що використовувались у процесі тренування. Навчальна вибірка містить інформацію про налаштування термостатів, стани освітлювальних приладів, налаштування системи безпеки, інформацію про присутність мешканців будинку в кожному приміщенні окремо та часові мітки моменту збереження даних налаштувань. Приклад формату даних у навчальній вибірці зображено у таблиці.

Таблиця. Фрагмент даних навчальної вибірки
\begin{tabular}{|c|c|c|c|c|c|c|c|}
\hline $\begin{array}{c}\text { Часо- } \\
\text { ва міт- } \\
\text { ка }\end{array}$ & $\begin{array}{c}\text { Рух y } \\
\text { кімн. 1 }\end{array}$ & $\begin{array}{c}\text { Рух у } \\
\text { кімн. 2 }\end{array}$ & $\begin{array}{c}\text { Світло } \\
\text { кімн. 1 }\end{array}$ & $\begin{array}{c}\text { Світло } \\
\text { кімн. 2 }\end{array}$ & $\begin{array}{c}\text { Темп. } \\
\text { кімн. 1 }\end{array}$ & $\begin{array}{c}\text { Темп. } \\
\text { кімн. 2 }\end{array}$ & $\begin{array}{c}\text { Режим } \\
\text { охоро- } \\
\text { ни }\end{array}$ \\
\hline $\begin{array}{c}15675 \\
19042\end{array}$ & TRUE & FALSE & TRUE & TRUE & 21 & 18 & FALSE \\
\hline $\begin{array}{l}15675 \\
23065\end{array}$ & TRUE & TRUE & FALSE & FALSE & 20 & 18 & FALSE \\
\hline $\begin{array}{l}15675 \\
35088\end{array}$ & FALSE & TRUE & TRUE & FALSE & 20 & 20 & FALSE \\
\hline
\end{tabular}

Із 7510 записів з набору історичних даних випадково вибрано п'ять записів, які видаляються з набору та не беруть участі у навчальній вибірці, а використовуються в процесі тестування навчання ШНМ.

Сформовано тестові вибірки для навчання алгоритмів ШНМ різних типів, які використовуватимуться у процесі керування побутовими приладами "розумного" будинку та встановленим термостатом для забезпечення оптимального температурного режиму, режиму освітлення та налаштування системи безпеки будинку.

Метод вибору оптимального типу штучної нейронної мережі. Ефективність роботи ШНМ безпосередньо залежить від іï типу, внутрішньої структури та специфіки розв'язуваної задачі. Наприклад, для розв'язання задач розпізнавання образів на зображеннях та відеопотоці - ефективно використовувати згорткові нейронні мережі [3], а для перекладу текстів, або програмування ботів, що ведуть діалоги з людиною - оптимальним вибором $є$ рекурентні нейронні мережі [12]. Тому постає питання вибору оптимальної структури штучної нейронної мережі, яка буде застосована для автоматизації керування температурним режимом, системою безпеки та освітленням у будинку. Початковим етапом вибору структури штучної нейронної мережі $є$ створення списку відомих типів штучних нейронних мереж. До такого списку, у розглянутому прикладі, належать: нейронна мережа прямого поширення [21]; рекурентна нейронна мережа [18]; довга короткочасна пам'ять [10]; вентильний рекурентний вузол [24]. Наступним кроком методу є генерування навчальної вибірки шляхом відкидання п'ятьох записів, що утворюють тестову вибірку, яка буде використовуватись в подальшому для обчислення помилки роботи алгоритму ШНМ порівняно 3 очікуваними даними. Наступним етапом методу є послідовне навчання за допомогою створеної навчальної вибірки та запуск навченої штучної нейронної мережі з подачею на вхід параметрів тестової вибірки та збере- 
женням отриманих вихідних результатів. Серед отриманих значень похибок кожного вихідного параметра, розраховується середнє значення, що є загальним значенням похибки використання конкретного типу ШНМ для розв'язання поставлених задач, яке порівнюється 3 найменшим отриманим середнім значенням похибки попередньо розглянутих типів штучної нейронної мережі. У разі, якщо це значення є меншим за попереднє поточна штучна нейронна мережа зберігається як найоптимальніша для розв'язання поставленої задачі, а середнє значення похибки зберігається як найоптимальніше на конкретний момент дослідження. Процес навчання, запуску та аналізу вихідних результатів роботи штучної нейронної мережі послідовно проводиться для кожного типу ШНМ зі списку, поки не буде проаналізовано всі типи.

У наведеному дослідженні побудований метод пошуку оптимального типу штучної нейронної мережі, за допомогою відповідних навчальних і тестових вибірок, послідовно застосовувався для розв'язання задач автоматизованого керування температурним режимом, режимом освітлення та налаштуваннями систем безпеки. Перевагою розробленого методу є використання єдиного набору історичних даних для формування навчальної та тестової вибірок за допомогою комбінування вхідних та вихідних параметрів для кожної поставленої задачі, що унеможливлює вплив на результати роботи алгоритму ШНМ специфіки даних, які використовувались у процесі тренування.

Особливості програмної реалізації методу. Програмна реалізація методу вибору оптимального типу ШНМ базується на використанні технології NodeJS [13], що зарекомендувала себе як швидка технологія опрацювання великого потоку одночасно згенерованих подій. Для реалізації алгоритму штучної нейронної мережі використано бібліотеку BrainJS [6], яка дає змогу гнучко налаштовувати параметри і типи ШНМ та проводити тренування алгоритму штучної нейронної мережі за допомогою навчальної вибірки. Для збереження даних навчальної вибірки використано нереляційну базу даних MongoDB [25].

Окрім цього, розроблено алгоритм пошуку оптимального типу ШНМ, який містить кроки навчання, випробування та аналізу результатів кожного типу штучної нейронної мережі, що дає змогу використати найефективніший тип ШНМ для розв'язання поставлених задач автоматизованого управління температурою, освітленням та системою безпеки будинку. Розроблено програмне забезпечення, яке дає змогу провести процеси навчання, випробування та отримати вихідні результати роботи алгоритму ШНМ кожного розглянутого типу для подальшого аналізу ефективності їх використання.

Обговорення результатів дослідження. Під час аналізу отриманих результатів дослідження, порівнявши їх, можна прийти до висновку, що для розв'язання різних поставлених задач перед системою "розумного" будинку доцільно використовувати різні типи штучних нейронних мереж, залежно від специфіки поставленої задачі. Для налаштування температури повітря у приміщеннях помешкання, обладнаного системою "розумного" будинку, найоптимальнішим вибором є використання нейронних мереж прямого поширення [8]. Цей вибір забезпечує похибку отриманих результатів з бажаними у межах менше 5 \%. Для налаштування освітлювальних приладів помешкання, 3 встановленою системою "розумного" будинку, найменша похибка між отриманими та бажаними результатами роботи алгоритму ШНМ, була отримана при використанні рекурентних нейронних мереж [16]. Це рішення забезпечує отримання похибки менше $10 \%$. Для забезпечення оптимального режиму системи безпеки помешкання, обладнаного системою "розумного" будинку, найоптимальнішим вибором $є$ штучна нейронна мережа типу "Довга короткочасна пам'ять" [11], що забезпечує похибку між отриманими та бажаними результатами менше $8 \%$. Унаслідок порівняння отриманих похибок з отриманими реальними та бажаними налаштуваннями побутових приладів у будинку, використання вентильних механізмів рекурентних нейронних мереж [26], під час розв'язання поставлених задач $\epsilon$ не актуальним рішенням, з огляду на великі показники похибки роботи алгоритму штучної нейронної мережі.

Отже, проаналізовано результати застосування різних типів штучних нейронних мереж для розв'язання поставлених задач, розраховано значення похибки між отриманими та очікуваними вихідними результатами та вибрано оптимальні типи ШНМ для кожної окремо поставленої задачі.

\section{Висновки}

Розроблено метод вибору оптимального типу ШНМ, ідеєю якого є практичне застосування декількох типів ШНМ та подальшого розрахунку похибки роботи кожного типу $з$ використанням ідентичних наборів даних для навчання ШНМ, що унеможливлює вплив на результати роботи алгоритму специфіки даних у навчальній вибірці. Розроблено програмне забезпечення, яке дає змогу провести процеси навчання, випробування та отримати вихідні результати роботи алгоритму ШНМ. 3 аналізу отриманих результатів випливає, що неможливо створити одну універсальну ШНМ для комплексного розв'язання поставлених задач з автоматизованого керування температурними режимами, освітлювальними приладами та системи безпеки у помешканні, оснащеному системою "розумного" будинку. Для розв'язання кожної з поставлених задач потрібно використати окрему штучну нейронну мережу такого типу, яка забезпечує найкращі показники роботи, відповідно до специфіки вирішуваної задачі.

\section{References}

1. Amazon Echo. (2019). Amazon Inc. Retrieved from: https://www.amazon.com.

2. Amit, Badlani, \& Surekha, Bhano. (2011). Smart Home System Design based on Artificial Neural Networks. Proceedings of the World Congress on Engineering and Computer Science (WCECS2011), (Vol. I). San Francisco, USA, October 19-21, 106-111.

3. Ayyadevara, V. K. (2018). Convolutional Neural Network. In: Pro Machine Learning Algorithms. Apress, Berkeley, CA, 179-215.

4. Biljana, L., Risteska, Stojkoska, \& Kire, V., Trivodaliev, A. (2017, January). Review of Internet of Things for smart home: Challenges and solutions. Journal of Cleaner Production, 140(3), 1454-1464.

5. Boreiko, O. Y., Teslyuk, V. M., Zelinskyy, A., \& Berezsky, O. (2017). Development of models and means of the server part of the system for passenger traffic registration of public transport in the "smart" city. In: Eastern-European Journal of Enterprise Technologies, 1(2-85), 40-47. 
6. Brain, J. S. (2019). Retrieved from: https://brain.js.org/.

7. Design of a Prototype Neural Network for Smart Homes and Energy Efficiency. (2019). Tobias Teich, Falko Roessler, Daniel Kretz, Susan Frank.

8. Dixon, M. F., Halperin, I., \& Bilokon, P. (2020). Feedforward Neural Networks. In: Machine Learning in Finance. Springer, Cham. https://doi.org/10.1007/978-3-030-41068-1 4

9. Google Home. (2019). Alphabet Inc. Retrieved from: https://store.google.com/us/product/google_home.

10. Graves, A. (2012). Long Short-Term Memory. In: Supervised Sequence Labelling with Recurrent Neural Networks. Studies in Computational Intelligence, (Vol. 385). Springer, Berlin, Heidelberg.

11. Graves, A. (2012). Long Short-Term Memory. In: Supervised Sequence Labelling with Recurrent Neural Networks. Studies in Computational Intelligence, (Vol. 385. Springer, Berlin, Heidelberg. https://doi.org/10.1007/978-3-642-24797-2 4

12. Jaeger, D., Jung, R. (2015). Recurrent Neural Network. In: Encyclopedia of Computational Neuroscience. Springer, New York, NY.

13. Joshua Johanan. (2014). Building Scalable Apps with Redis and Node.js, (Vol. 1). Birmingham: Packt Publishing Ltd., 297 p.

14. Kazarian, A., Teslyuk, V., Tsmots, I., \& Tykhan, M. (2019). Implementation of the Face Recognition Module for the "Smart" Home Using Remote Server. In: Advances in Intelligent Systems and Computing III, AISC 871, Springer, 17-27.

15. Kazarian, A., V., Tsmots, I., \& Teslyuk, V. (2017). Intelligent house as a service and its practical usage for home energy efficiency. In: 12th International Scientific and Technical Conference on Computer Sciences and Information Technologies (CSIT2017), (Vol. 1), pp. 220-223.

16. Ketkar, N. (2017). Recurrent Neural Networks. In: Deep Learning with Python. Apress, Berkeley, CA. https://doi.org/10.1007/978-14842-2766-4 6
17. Klug Home. (2019). Indiegogo, Inc. Retrieved from: https://www.indiegogo.com/projects/klug-home-world-s-smallestintuitive-home-hub\#l.

18. Marhon, S. A., Cameron, C. J. F., \& Kremer, S. C. (2013). Recurrent Neural Networks. In: Bianchini, M., Maggini, M., \& Jain, L. (Eds). Handbook on Neural Information Processing. Intelligent Systems Reference Library, (Vol. 49). Springer, Berlin, Heidelberg.

19. MERLSense Data. (2007). Mitsubishi Electric Research Labs. Retrieved from: https://sites.google.com/a/drwren.com/wmd/.

20. Meulen, R. (2017). Gartner Says 8.4 Billion Connected "Things" Will Be in Use in 2017, Up 31 Percent From 2016. Rob Meulen. Gartner. Retrieved from: https://www.gartner.com/en/newsroom/press-releases/2017-02-07-gartner-says-8-billion-connectedthings-will-be-in-use-in-2017-up-31-percent-from-2016

21. Monteiro da Silva, A., \& Sussner, P. (2008). A Brief Review and Comparison of Feedforward Morphological Neural Networks with Applications to Classification. In: Kůrková, V., Neruda, R., Koutník, J. (Eds). (2008). Artificial Neural Networks, (ICANN2008). Lecture Notes in Computer Science, (Vol. 5164). Springer, Berlin, Heidelberg.

22. Nest Thermostat. (2019). Nest Corporation. Retrieved from: https://nest.com.

23. Netatmo. (2019). Netatmo. Retrieved from: https://www.netatmo.com.

24. Pawlicki, M., Marchewka, A., Choraś, M., \& Kozik, R. (2020). Gated Recurrent Units for Intrusion Detection. In: Choraś, M., Choraś, R. (Eds). Image Processing and Communications, (IP\&C2019). Advances in Intelligent Systems and Computing, (Vol. 1062). Springer, Cham.

25. Prasad Reddy, K. S. (2017). Working with MongoDB. In: Beginning Spring Boot 2. Apress, Berkeley, CA.

26. Zhou, G., Wu, J., Zhang, C., et al. (2016). Minimal gated unit for recurrent neural networks. Int. J. Autom. Comput, 13, 226-234. https://doi.org/10.1007/s11633-016-1006-2

V. M. Teslyuk, A. G. Kazarian

Lviv Polytechnic National University, Lviv, Ukraine

\section{DEVELOPMENT OF OPTIMAL ARTIFICIAL NEURAL NETWORK TYPE SELECTION METHOD FOR USAGE IN SMART HOME SYSTEMS}

The optimal artificial neural network type selection method has been developed, based on the idea of the practical usage of several types of artificial neural network and further calculation of the error for each type using identical data sets for artificial neural network training, which eliminates the influence of data specificity algorithm in the training sample. This method allows searching for the optimal type of artificial neural network for the control of household appliances in the house, regardless of the automation task type (temperature, lighting, safety, etc.). The paper considers the process of creating software that can be used for training, testing and obtaining the initial results of the artificial neural network algorithm. The algorithm of the artificial neural network is used for automated calculation of the optimal temperature conditions values in the rooms of the house, the parameters of the lighting fixtures and the modes of the home security system work. The relationship between changes in neural network type and quantity of the artificial neural network inner layers is considered and the number of neurons on each inner layer and changes of the automatically calculated parameters error related to the settings in comparison to the expected results. Solving each individual problem with the help of smart home systems requires the usage of different machine learning algorithms. The large amount of data generated in smart home systems and the variety of types and formats of this data do not allow creating a universal automated mechanism using artificial intelligence algorithms that would solve problems of safety, energy efficiency and maintenance of comfortable living conditions. Therefore, the usage of the proposed method of choosing the optimal neural network type, which is best suited to solve a particular problem, provides high efficiency of smart home systems with minimal difference of automated solutions compared to human decisions.

Keywords: smart home systems; machine learning; artificial intelligence; neural network of direct propagation; recurrent neural network; long short-term memory; valve recurrent node. 